УДК 338.2

DOI $10.21661 / \mathrm{r}-116639$

\title{
C.H. Сачук
}

\section{ПЕРСПЕКТИВЫ РАЗВИТИЯ ОТКРЫТЫХ ИННОВАЦИЙ В УПРАВЛЕНИИ ПРОЕКТАМИ}

Аннотация: с управленческой точки зрения процесс организационных изменений от закрытых к открытылм инновациям является одним из актуальных проблем в межорганизационном сотрудничестве, потому что компаниям необходимо внедрять новые организационные методики. В данном контексте автор предлагает рассмотреть управление проектами в рамках модели открытых инноваций. В статье рассмотрен авторский подход в исследовании практики управления проектами в открытых инновационных проектах и их влияние на традиционнье методы управления проектами.

Ключевые слова: модель открытых инноваций, управление проектами, открытые инновационные проекты, стратегическое управление.

\section{S.N. Sachuk}

\section{PROSPECTS FOR THE DEVELOPMENT OF OPEN INNOVATION IN PROJECT MANAGEMENT}

Abstract: from a management perspective, the organizational change process from closed to open innovations is one of actual problems in an inter-organizational cooperation, because companies need to introduce new organizational methods. In this context, the author proposes to consider project management under the model of open innovations. The article describes the author's approach in the study of project management in open innovation projects and their impact on traditional methods of project management.

Keywords: the model of open innovations, project management, open innovative projects, strategic management. 
В современных компаниях инновации считаются основным фактором для поддержания высокой прибыльности и обеспечения устойчивого роста. Традиционно производственные предприятия разрабатывали новые технологии для своей продукции, полагаясь исключительно на собственные возможности, преследуя относительно «закрытые» инновационные стратегии, что означает ограниченные взаимодействия с внешней средой. В сегодняшних условиях данная модель больше не является устойчивой, из-за глобальной конкуренции, поскольку компании все больше стремятся к сотрудничеству с внешними партнерами и установлению межорганизационных отношений.

В настоящее время растет число компаний интегрированных стратегий открытых инноваций в инновационные процессы, поэтому многие научные исследования стремятся исследовать организационные последствия отрытых инноваций и понимание проблем, связанных с сотрудничеством через организационные границы и трудностей в достижении совместных целей. За последние десятилетия множество исследований посвящены открытым инновациям, проектному управлению и проблемам налаживанию связи между этими основными направлениями [1, с. 47].

Управление проектами представляет собой сложный и взаимосвязанный комплекс в различных областях компетенций, такими как, управление изменениями, организационным управлением и процессом управления.

Термин «открытые инновации» был введен впервые Генри Чесбро в 2003 году для описания инновационных процессов, в рамках которых предприятие

широко взаимодействует с окружающей средой, что приводит к распространению внешних знаний. Другими словами, открытые инновации - это использование целевых потоков знаний для ускорения внутренних инноваций и расширения рынков и соответственно для внешнего использования инноваций.

Эту парадигму можно понимать как противоположность закрытой инновационной модели, которая считает внутренние НИОКР ценным стратегическим активом и грозным барьером для входа конкурентов на многих рынках [2, с. 102]. 
Закрытая инновационная модель относится к традиционному инновационному процессу. Различия между закрытыми инновациями и правилами открытых инноваций представлены в таблице 1.

Контрастные принциипь закрытых и открытыхых инноваций.

\begin{tabular}{|c|l|l|}
\hline № п/п & \multicolumn{1}{|l}{ Принципы закрытых инноваций } & \multicolumn{1}{|c|}{ Принципы открытых инноваций } \\
\hline 1 & $\begin{array}{l}\text { Чтобы получить прибыль от НИОКР, } \\
\text { мы должны раскрыть, развить, произ- } \\
\text { вести и доставить его сами }\end{array}$ & $\begin{array}{l}\text { Внешние НИОКР могут создать значи- } \\
\text { тельную ценность; внутренние НИОКР } \\
\text { необходимы, чтобы утверждать какую-то } \\
\text { часть этой стоимости }\end{array}$ \\
\hline 2 & $\begin{array}{l}\text { Если мы первыми внедряем иннова- } \\
\text { ции, мы победим }\end{array}$ & $\begin{array}{l}\text { Построение эффективной бизнес-модели } \\
\text { лучше, чем добраться до рынка первыми }\end{array}$ \\
\hline 3 & $\begin{array}{l}\text { Если мы создадим лучшие идеи в ин- } \\
\text { дустрии, мы победим }\end{array}$ & $\begin{array}{l}\text { Если мы наилучшим образом используем } \\
\text { внутренние и внешние идеи, мы победим }\end{array}$ \\
\hline 4 & $\begin{array}{l}\text { Мытеллектуальную собственность } \\
\text { ИС) так, чтобы наши конкуренты не } \\
\text { получали прибыль от наших идей }\end{array}$ & $\begin{array}{l}\text { Мы должны получать прибыль от исполь- } \\
\text { зования другими нашей интеллектуальной } \\
\text { собственности, и мы должны приобретать } \\
\text { чужун интеллектуальную собственность, } \\
\text { когда продвигает нашу собственную } \\
\text { бизнес-модель }\end{array}$ \\
\hline
\end{tabular}

Открытая бизнес-модель позволяет компаниям обнаружить большее количество идей, контролировать свою интеллектуальную собственность. В последние годы обнаруживается все больше факторов, убеждающих компании в уязвимости закрытой бизнес-модели [3, с. 337].

Основными факторами можно назвать:

1) сложность контроля своих собственных идей и ноу-хау, из-за роста мобильности работников умственного труда;

2) со стратегической точки зрения, растущее значение кластеров и горизонтальных деловых связей между компаниями;

3) возникающее присутствие частного венчурного капитала.

Кроме того, в соответствии с экономической точки зрения закрытая бизнесмодель не является жизнеспособной, это наглядно видно на рисунке 1, который показывает, как доходы на рынке не покрывают роста затрат на разработку, изза короткой жизни продукта на рынке. 


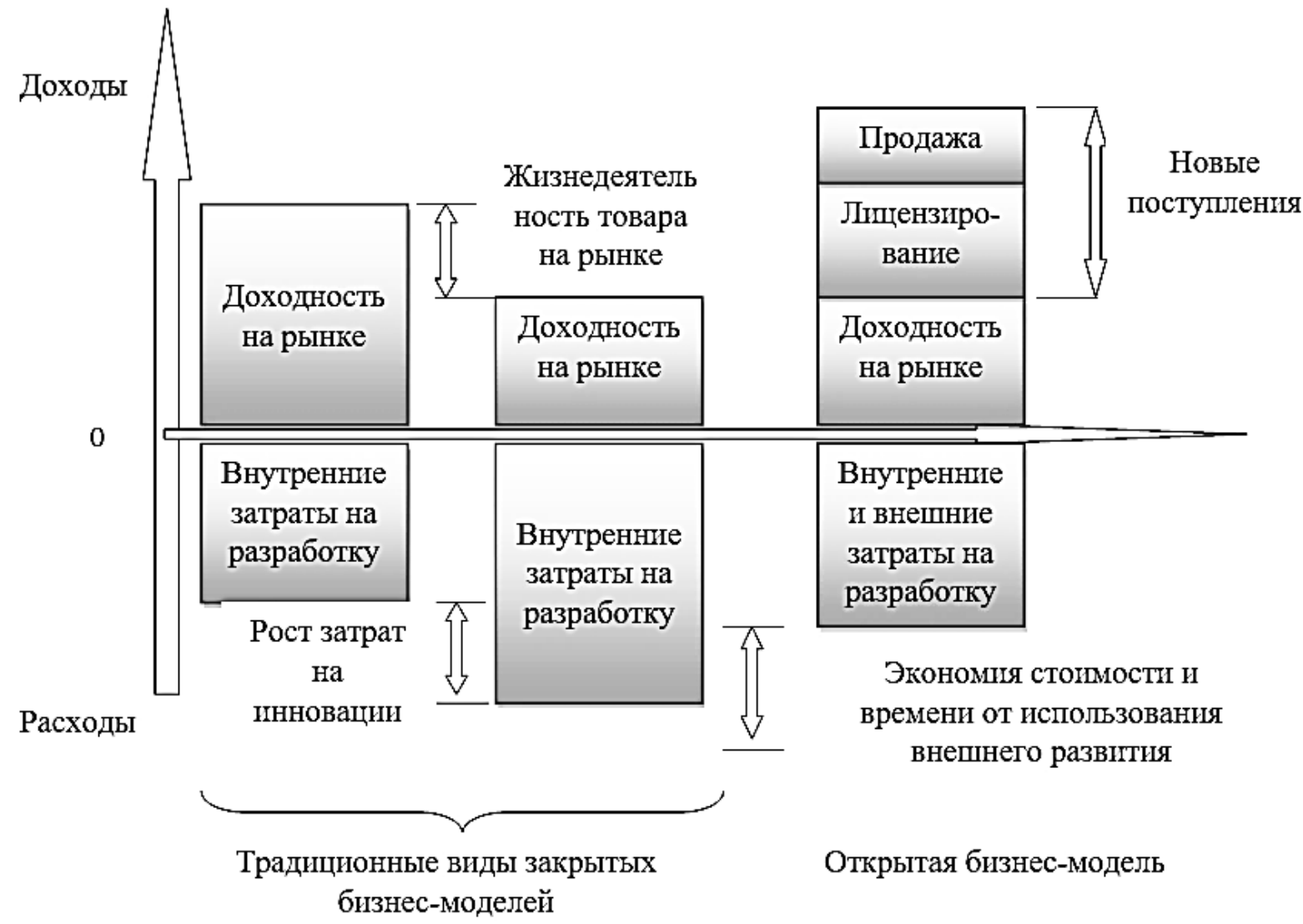

Рис. 1. Схема сравнения бизнес-моделей

В контексте нового подхода фирмы открывают свои границы для других внешних источников знаний, таких как заказчики, вузы, конкуренты, поставщики, консультанты, проектные и научно-исследовательские институты для того, чтобы использовать передовые идеи и технологии и снижать затраты на разработку инноваций. У компаний, использующих модель открытых инноваций, появляются новые возможности для получения прибыли в результате участия в других сегментах, через сотрудничество в доходе от лицензирования, совместных предприятий.

Уникальность этой концепции заключается в возможности для инновационных компаний в создании новых организационных структур и процессов. Модель открытых инноваций обеспечивает более целостный взгляд на внешнее сотрудничество и коммерциализацию.

Ядром модели является способность фирмы создавать новые знания, эксплуатирующих внешние источники инноваций, таких как клиенты, контрагенты 
и конкуренты. Таким образом, открытые инновации используют не только внешние источники, когда они доступны, но также основываются на реализации внутренней стратегии компании, которая приведет к формированию внешних знаний $[4$, c. 95$]$.

Что касается человеческого фактора, было бы полезно проанализировать роль менеджера проектов его навыки, необходимые для того, чтобы преодолеть возможные трудности при использовании модели открытых инноваций на практике. Открытые инновации можно характеризовать как входящие открытые инновации, к которым относится получение внешних знаний с целью создания и разработки новых продуктов/услуг, когда внутренние и внешние источники технологий используются для повышения внутренней инновационной практики и исходящие открытые инновации - это когда проекты, направлены на переход к новым рынкам по-разному, через спин-офф предприятия или через лицензирование с целью использования внешних внутренних знаний [5, с. 3054].

В последние годы многие компании отмечают, что партнерские отношения с другими организациями являются основополагающей предпосылкой для их успеха. Традиционно, проекты НИОКР используются фирмами для управления инновационными процессами и важно усилить анализ в целях выявления источников инноваций. Изучение открытых инноваций на уровне проекта позволяет описать и проанализировать новые аспекты, которые можно получить при условии участия партнеров проекта для того, чтобы развивать и генерировать идеи $[6$, c. 53].

Сущность открытых инновационных проектов в том, что различные партнеры, такие как научные круги, промышленность, правительство представляют совместный контекст, поскольку взаимодействие и активное участие всех партнеров влияет на управление проектами. Необходимо координировать и управлять инновационными процессами из-за конфликтов между участниками, которые усиливаются за счет открытого обмена знаниями. 
Что касается человеческой стороны, в последнее время в открытых инновационных проектах увеличилось количество участников из различных организаций с разным опытом, тем самым становятся все более сложными для управления.

\section{Список литературы}

1) Зотов Ф.П. Способ управления проектами изменений системы управления промышленным предприятием // Эффективные системы менеджмента - гарантии устойчивого развития. - 2016. - Т. 1. - №5. - 47 с.

2) Козлов А.С. Руководство управлением проектами: как руководителям организации контролировать и направлять проектную деятельность // Управление проектами и программами. - 2011. - №2. - С. 94-104.

3) Ответчикова И.С. Управление бизнес-процессами в рамках концепции единой системы управления проектами // Инновации и инвестиции. - 2013. №6 (35). - C. 335-339.

4) Томорадзе И. Управление проектами как стадия процессного управления / И. Томорадзе, А. Дмитрик // Проблемы теории и практики управления. 2013. - №2. - C. 93-100.

5) Kosyakova I.V., Forrester S.V., Ustinova G.Kh., Ronzhina N.V., Suraeva M.O. Human capital in the innovative // International Electronic Journal of Mathematics Education. - 2016. - T. 11. - №8. - P. 3048-3065.

6) Zhabin A.P., Suraeva M.O., Evdokimov A.N., Polynova K.V., Akopyan D.A., Chertykovtsev V.K., Grigoryants I.A. Crisis management on the basis of the marketing approach for development of innovative potential of the organization // International Review of Management and Marketing. - 2016. - T. 6. - №6. - P. 51-56.

Сачук Светлана Николаевна - соискатель ФГБОУ ВО «Самарский государственный экономический университет», Россия, Самара.

Sachuk Svetlana Nikolaevna - applicant FSFEI of HE "Samara State Economic University", Russia, Samara. 